\title{
Tobacco Habits, Oral Mucosal Lesions and Counselling Provided to Support Staff of Educational Institutions Situated in Greater Noida, Uttar Pradesh, India: A Cross-Sectional Study
}

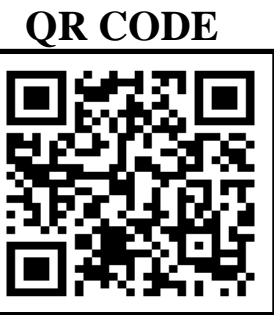

PANKAJ NAGAR ${ }^{* 1}$, LILY ABRAHAM², IRINA BHATI ${ }^{1}$

INTRODUCTION: Tobacco has approximately one billion users and claims the life of one person every six seconds on an average.

AIM: To assess the tobacco habits and related oral mucosal lesions and tobacco cessation counselling provided to the support staff of various educational institutions located in Greater Noida, Uttar Pradesh, India.

MATERIALS AND METHOD: Data was collected in two steps. The first step included data collection using the Global Adult Tobacco Survey (GATS), 2011 which was modified according to the needs of the population. The second step included recording of Oral Mucosal Lesions through the "Oral Mucosa" component of the WHO Oral Health Assessment Form(1997) by a standardized investigator. Data was tabulated and the student's t-test and Spearman's correlation were applied to find out significant associations, if any. Data was analysed using SPSS version 21.0 and significance (p) was kept significant at $\leq 0.05$.

RESULTS: Tobacco consumption in any form was found in $47.1 \%$ subjects consisting of 37 males (90.2\%)and 4 females (9.8\%). Smoking was found in 16 subjects (18.4\%) comprising of 13 males $(14.9 \%)$ and 3 females $(3.4 \%)$. Lesions were observed in $58.5 \%$ of the population, with the most common lesion being leucoplakia $(27 \%)$, followed by any other lesion $(24 \%)$ and malignant lesions $(7 \%)$. A positive correlation was observed in three variables; the first being an increased willingness to quit with increased current consumption $(\mathrm{r}=0.67)$, followed by willingness to quit due to presence of a lesion ( $\mathrm{r}=0.7 \mathrm{l})$ and willingness to quit due to provision of any type of counselling $(\mathrm{r}=0.70)$.

CONCLUSION: It is important that efforts are directed towards reducing and subsequently eliminating tobacco consumption among support staff of various educational schools who have a high percentage of tobacco intake.

KEYWORDS: Tobacco, Cessation, Relapse

\begin{abstract}
INTRODUCTION
Tobacco, the widely recognised epidemic, has more than one billion users and its use claims an average of one person every six seconds and also accounts for one in 10 adult deaths worldwide globally. It finds itself as risk factor for six of the eight leading cause of deaths across the world. This killer disease has its most of its users low-and middle-income countries, and especially in rural areas of India, where the use of bidi and smokeless tobacco is quite prevalent., ${ }^{1,2}$ Various authors have studied its deleterious effects on the health of individuals, and it shows variation in its use according to area and gender. $3,4,5$
\end{abstract}

Tobacco use in any form has deleterious effects on the body and it affects the oral cavity, causing oral cancer and various premalignant lesions and conditions. It also affects the heart, liver and lungs, and has been acknowledged as a major risk factor for heart attacks, strokes and various diseases involving the respiratory system e.g. (COPD, Bronchitis, emphysema, etc).

In India, data on oral lesions as a result of tobacco habits varies from area to area and it varies from $26.8 \%^{6}$ and $41.2 \%{ }^{7}$ in South India to $30.03 \%^{8}$ amongst fishermen in Gujarat to $16.8 \% 9$ amongst patients visiting a dental college in Northern India and it reflects the different kinds of tobacco consumptions and habits prevalent in various parts of India.

The support staff (peons, drivers, mess workers, sweepers, gatekeepers, assistants) are an essential part in the overall functioning of all educational institutions. However, it is observed that little or no importance is paid on their overall and tobacco habits. Hence, this study aims to assess the tobacco habits and related oral mucosal lesions and tobacco cessation counselling provided to the support staff of various educational institutions located in Greater Noida, Uttar Pradesh, India.

\section{MATERIALS AND METHOD}

A cross-sectional study was conducted on support staff (peons, drivers, mess workers, sweepers, gatekeepers, assistants) of various educational institutions situated in Greater Noida, Uttar Pradesh and willing to participate in the study and not having any formal dental education (degree/diploma) were included in the study. Prior to the commencement of the study, an

(C) Pankaj Nagar et al. This is an open access article distributed under the terms of the Creative Commons Attribution License CC-BY-NC 4.o, which permits unrestricted use, distribution and reproduction in any medium, provided the use is not commercial and the original author(s) and source are cited. Submitted on: 30-Jun-2021; Accepted on: 28-Jul-2021 
ethical clearance was duly taken from the institution where the study was being conducted. The study was conducted from $1^{\text {st } J a n u a r y, ~} 2018$ to $31^{\text {st }}$ March,2019 and willing participants were requested to sign a consent form that was written in Hindi, which was the native language of the support staff. A total of 87 subjects $(55$ males, 32 females) were selected through convenience sampling.

Data was collected in two steps. The first step included entering data in the Global Adult Tobacco Survey (GATS), 201110 which was modified according to the needs of the population and an additional questionnaire that asked whether the college provided any tobacco cessation counselling to them and if the support staff was interested in the same (figure 1). The questionnaire were both pre-validated and pre-tested prior to data collection.

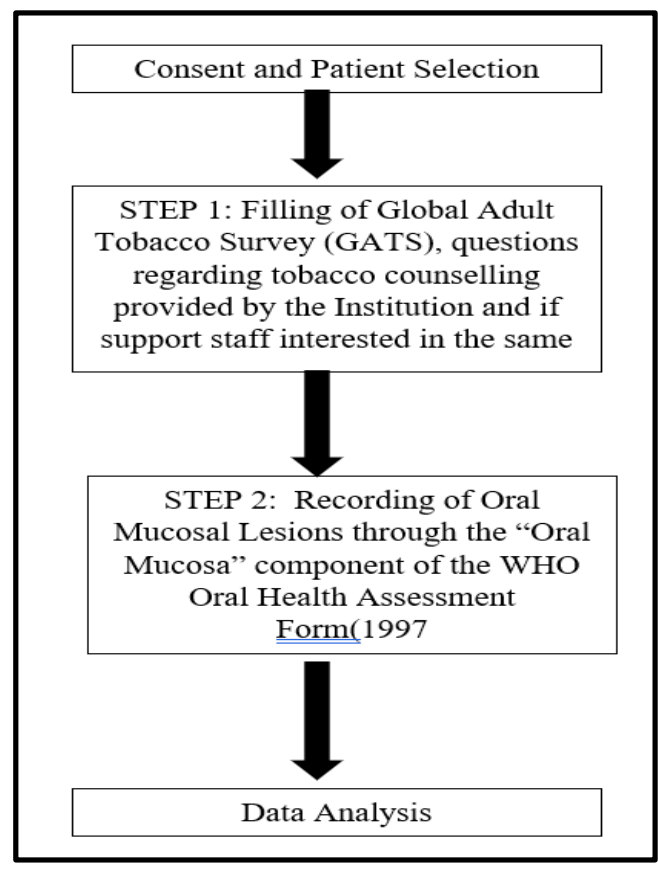

Figure 1. Study Protocol

The second step included recording of Oral Mucosal Lesions through the "Oral Mucosa" component of the WHO Oral Health Assessment Form(1997)" by the investigator himself, who was calibrated by prior to commencement of the study.

A pilot study was conducted amongst five subjects to validate the questionnaires and make subsequent adjustments. The data of these subjects was analysed with the main study participants and not included in the final analysis.

Data was tabulated and the student's t-test and Spearman's correlation were applied to find out significant associations, if any. Data was analysed using SPSS version 21.0 and significance (p) was kept significant at $\leq 0.05 .{ }^{12}$

\section{RESULT}

The support staff belonging to various educational schools in Greater Noida comprised of 87 subjects $(55$ males, 32 females), and a tobacco consumption habit in any form, was found in $41(47.1 \%)$ subjects which consisted of 37 males (90.2\%)and 4 females (9.8\%). The prevalence of smoking in this present study was found in 16 subjects $(18.4 \%)$ comprising of 13 males (14.9\%) and 3 females(3.4\%) (figure 2).

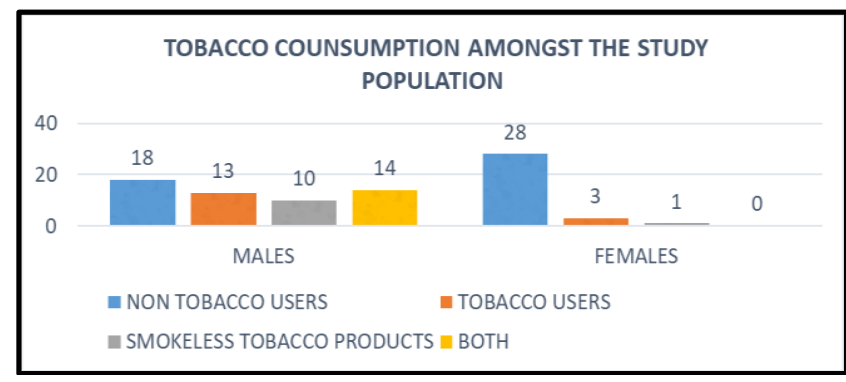

Figure 2. Tobacco Consumption Amongst Study Population

It was revealed that among smokers, there were $12.2 \%$ past smokers, and $17.1 \%$ past smokeless tobacco users. An encouraging 39\% attempted to quit at some time, yet only $29.7 \%$ males and $2.4 \%$ females received any cessation advice from a doctor $(\mathrm{p}=0.01)$. Significant differences among $24.4 \%$ males and $2.4 \%$ females was observed when asked whether they were thinking to quit smoking due to the warnings given on the packs (table 1)

The prevalence of lesions among the tobacco users is depicted in figure 3. Lesions were observed in $58.5 \%$ of the observed population, with the most common lesion being leucoplakia (27\%), followed by any other lesion (24\%) and malignant lesion [(oral cancer, $7 \%)$, figure 3]

A total of 20 males (36.3\%) ever attended any tobacco cessation counselling, while only $9(28.1 \%)$ females reported having undergone any type of tobacco cessation counselling (figure 4). Interestingly, 50 males 


\begin{tabular}{|c|c|c|}
\hline \multirow[t]{2}{*}{ QUESTION } & \multicolumn{2}{|c|}{ TOBACCO USERS } \\
\hline & MALES(n,\%) & FEMALES(n,\%) \\
\hline 1. Past smokers & $5(12.2)$ & o \\
\hline $\begin{array}{l}\text { 2. Past smokeless } \\
\text { tobacco users }\end{array}$ & $7(17.1)$ & o \\
\hline $\begin{array}{l}\text { 3. Attempts to quit } \\
\text { smoking (last } 12 \\
\text { months) }\end{array}$ & 16(39) & o \\
\hline $\begin{array}{l}\text { 4. Received } \\
\text { cessation advice } \\
\text { from doctor }\end{array}$ & $12(29.7)$ & $1(2.4)$ \\
\hline $\begin{array}{c}5 . \text { Visits to } \\
\text { dentist/doctor in } \\
\text { the past } 12 \text { months }\end{array}$ & $14(34.2)$ & $6(14.6)$ \\
\hline $\begin{array}{l}\text { 6. Would it help to } \\
\text { quit the habit if } \\
\text { tobacco counselling } \\
\text { is provided by the } \\
\text { institution? }\end{array}$ & $26(63.4)$ & $3(7 \cdot 3)$ \\
\hline $\begin{array}{l}\text { 7. Noticing health } \\
\text { warnings on } \\
\text { tobacco/bidi packs? }\end{array}$ & $13(31.7)$ & $2(4.9)$ \\
\hline $\begin{array}{c}\text { 8. Thinking about } \\
\text { quitting because of } \\
\text { warnings }\end{array}$ & $10(24.4)$ & $1(2.4)$ \\
\hline
\end{tabular}

Table 1. Information Regrading Smoking History among the Subjects

and 23 females reported that they would like to attend/re-attend another counselling and the difference was found to be statistically significant $\left(\mathrm{p}=0.03^{*}\right)$.

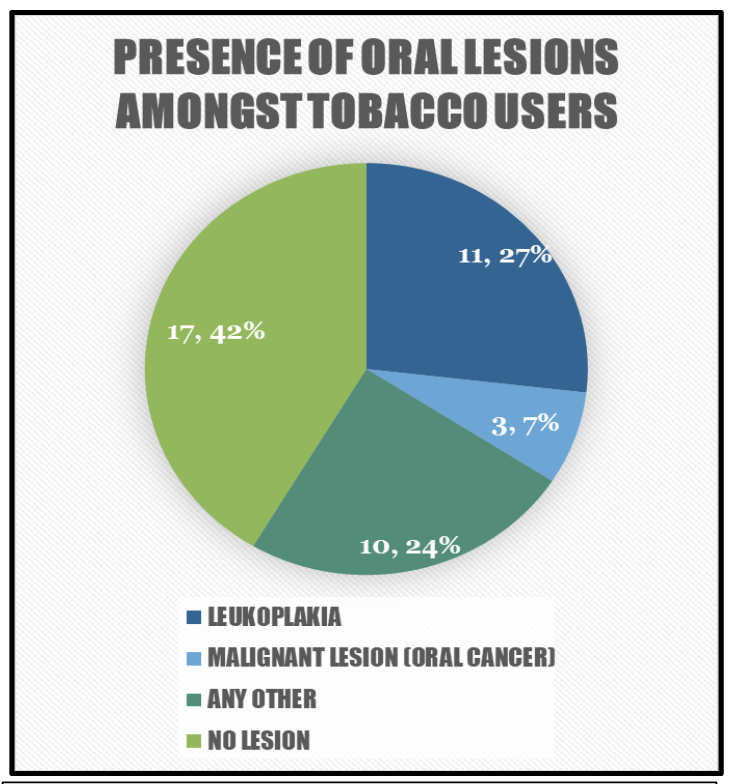

Figure 3. Person/source from Which the 29 Tobacco Users Received their Counselling
When asked about the person/source from which the twenty nine study subjects received their counselling, it was revealed that most counsellings $(41 \%)$ were provided by the dentist, followed by NGO's $(28 \%)$ and students(14\%). $17 \%$ of the subjects reported attending a common heath talk given by various organizations with no focus on individuals. No significant differences were observed while comparing the above-mentioned data (figure 5).

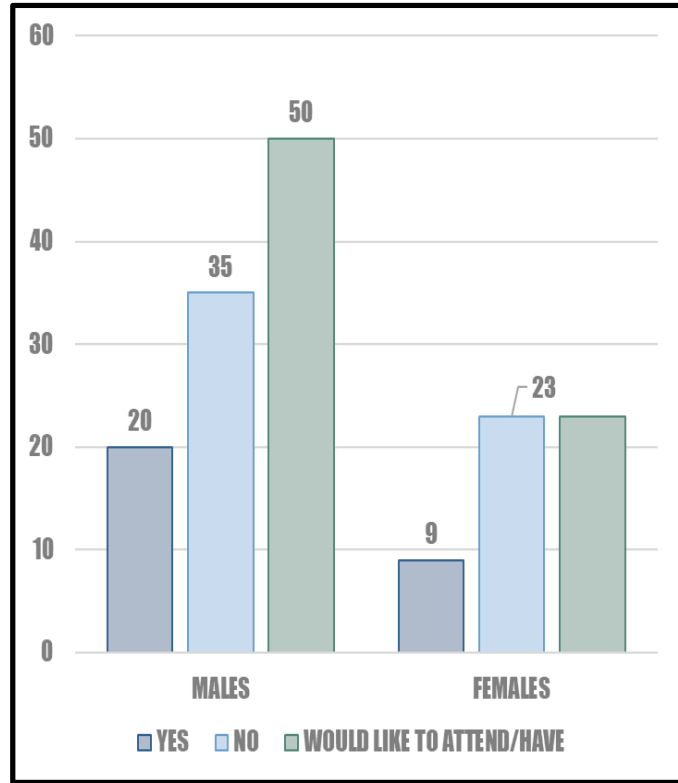

Figure 4. Tobacco Cessation Counselling among the Subjects

Upon application of the Spearman's Correlation, a positive correlation was observed in three variables; the first being an increased willingness to quit with increased current consumption $(\mathrm{r}=0.67)$, followed by willingness to quit due to presence of a lesion $(\mathrm{r}=0.71)$ and willingness to quit due to provision of any type of counselling $(\mathrm{r}=0.7 \mathrm{O})$, (table 2$)$.

\section{DISCUSSION}

As per the results of the present study, tobacco consumption habit in any form, was found in $47.1 \%$ subjects and this is lesser as compared to the reported prevalence of any tobacco use by Bhan $\mathrm{N}$. and colleagues which remained between $61.5 \%$ to $62.7 \%$ among people belonging to low socio-economic status. ${ }^{13}$ Although bidi smoking is on the decline, higher odds of bidi smoking were found among males, older people, and among those belonging lower socioeconomic status. Another factor for the uptake of bidi smoking is its easy availability and it lower cost. 
The prevalence of smoking in this present study was found observed in $18.4 \%$ of the subjects and is lower in comparison to Garrett BE et al., 15 who reported 31.6\% smoking prevalence among people with no high school diploma; and in agreement to Jindal SK et al. who reported a prevalence of $15.6 \%$ ever smokers. ${ }^{16}$

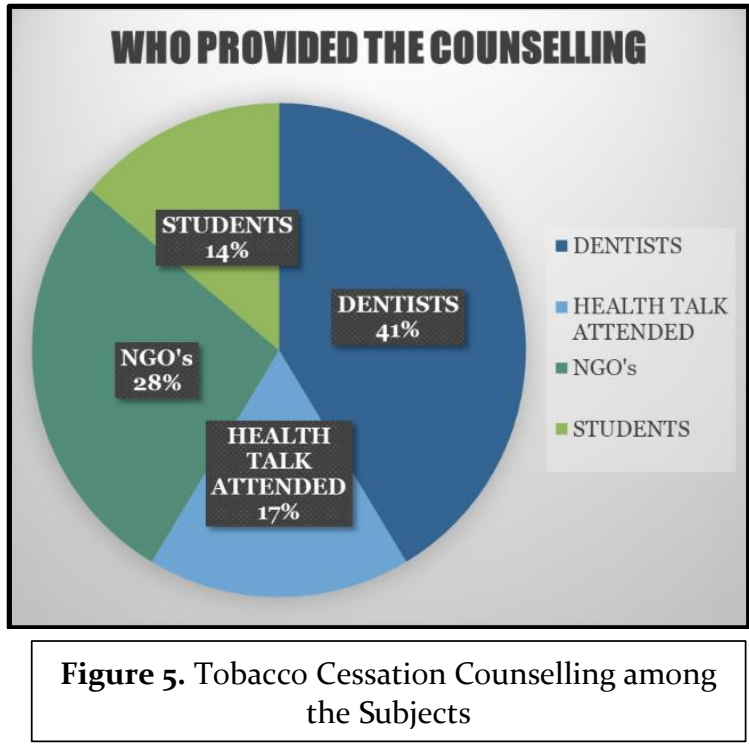

It was observed that $39 \%$ of the subjects attempted to quit smoking in the last 12 months; yet were unable to do so. These findings are in agreement to Kar SS et al., ${ }^{17}$ who reported a willing to quit all forms of tobacco in $52.2 \%$ of their study population. In addition, Srivastava $\mathrm{S}$ et al. reported that among $42 \%$ of people who made an attempt to quit tobacco; only $42 \%$ were successful in doing so; leading to a relapse in $58 \%$ of tobacco users. ${ }^{18}$ Nicotine dependency among the people needs to be addressed properly and it is possible that due to the low socio economic status, these people cannot afford to purchase Nicotine Replacement Therapy (NRT) or any other means of medication to help quit this habit. Also, the nature of their job also promotes them to increase their tobacco uptake to relieve stresses associated with it.

\begin{tabular}{|c|c|}
\hline VARIABLE & r \\
\hline Willingness to quit * & 0.67 \\
\hline current consumption & \\
\hline $\begin{array}{c}\text { Presence of Lesion * } \\
\text { Willingness to quit }\end{array}$ & 0.71 \\
\hline $\begin{array}{c}\text { Counselling (Any type) * } \\
\text { Willingness to quit }\end{array}$ & 0.70 \\
\hline
\end{tabular}

Table 2. Spearman's Correlation in Relation to Willingness to quit and Other Variables
Among the $33 \%$ of males and females who attended any form of health education, only $13.8 \%$ successfully quit the habit. Further efforts should be made to make the current smokers understand that smoking cessation is proven to decrease anxiety, stress, or depression and also improve the quality of life among tobacco users compared with those who continued to smoke tobacco. ${ }^{19}$

Oral lesions were observed in $58.5 \%$ of the subjects in the present study, with the most common being leukoplakia $(27 \%)$. These findings were lower as compared to $73.8 \%$ of oral lesions observed by Chandra $\mathrm{P}$ et $\mathrm{al}^{20}$ and higher as compared to the findings of Aslesh OP et al.(36.3\%). ${ }^{21}$ Variations in such percentages can be attributed to personal, geographical and religious preferences in tobacco intake among people.

\section{CONCLUSION}

As per the study results, it is important that efforts are directed towards reducing and subsequently eliminating tobacco consumption among support staff of various educational institutions who have a high percentage of tobacco intake. Tobacco cessation programmes (both governmental and nongovernmental) should also include and focus such population to reduce the global burden of disease.

Acknowledgement: The authors would like to that all participants and Mr. Gaurav Shahni for help with biostatistics.

\section{REFERENCES}

1. World Health Organisation. Tobacco Free Initiative (TFI): Tobacco facts. (Online Article). Available at: http://www.who.int/tobacco/mpower/tobaccofacts/e $\mathrm{n} /$. [Last accessed on $15^{\text {th }}$ December. 2020]

2. Sinha DN, Gupta PC, Pednekar MS. Tobacco Use In A Rural Area Of Bihar, India. Indian Journal of Community Medicine 2003;28(4):167-70.

3. Chinwong D, Mookmanee N, Chongpornchai J, Chinwong S. A Comparison of Gender Differences in Smoking Behaviors, Intention to Quit, and Nicotine Dependence among Thai University Students. J Addict. $2018 \quad$ Oct 24;2018:8081670. https://doi.org/10.1155/2018/8081670.

4. Smith PH, Bessette AJ, Weinberger AH, Sheffer CE, McKee SA. Sex/gender differences in smoking cessation: A review. Prev Med. 2016;92:135-40. https://doi.org/10.1016/j.ypmed.2016.07.013.

5. Yue Y, Hong L, Guo L, Gao X, Deng J, Huang J, et al. Gender differences in the association between cigarette 
smoking, alcohol consumption and depressive symptoms: a cross-sectional study among Chinese adolescents. Sci $\quad$ Rep. 2016;5:17959. https://doi.org/10.1038/srep17959

6. Patil PB, Bathi R, Chaudhari S. Prevalence of oral mucosal lesions in dental patients with tobacco smoking, chewing, and mixed habits: A cross-sectional study in South India. J Family Community Med. 2013;20(2):130-5. https://doi.org/10.4103/22308229.114777

7. Mathew AL, Pai KM, Sholapurkar AA, Vengal M. The prevalence of oral mucosal lesions in patients visiting a dental school in Southern India. Indian J Dent Res. 2008;19(2):99-103.

8. Chandroth SV, Venugopal HK, Puthenveetil S, Jayaram A, Mathews J, Suresh N et al. Prevalence of oral mucosal lesions among fishermen of Kutch coast, Gujarat, India. Int Marit Health. 2014;65(4):192-8. https://doi.org/10.5603/IMH.2014.0037.

9. Bhatnagar P, Rai S, Bhatnagar G, Kaur M, Goel S, Prabhat M. Prevalence study of oral mucosal lesions, mucosal variants, and treatment required for patients reporting to a dental school in North India: In accordance with WHO guidelines. Journal of Family \& Community Medicine 2013;20(1):41-48. https://doi.org/10.4103/2230-8229.108183.

10. Global Adult Tobacco Survey Collaborative Group. Tobacco Questions for Surveys: A Subset of Key Questions from the Global Adult Tobacco Survey (GATS), 2nd Edition. Atlanta, GA: Centers for Disease Control and Prevention, 2011

11. World Health Organization. (1997). Oral health surveys : basic methods, 4th ed. World Health Organization.

https://apps.who.int/iris/handle/10665/41905

12. IBM Corp. Released 2012. IBM SPSS Statistics for Windows, Version 21.o. Armonk, NY: IBM Corp.

13. Bhan N, Karan A, Srivastava S, Selvaraj S, Subramanian SV, Millett C. Have Socioeconomic Inequalities in Tobacco Use in India Increased Over Time? Trends From the National Sample Surveys (2000-2012). Nicotine Tob Res. 2016;18(8):1711-8. https://doi.org/10.1093/ntr/ntwo92.

14. Mbulo L, Palipudi KM, Smith T, Yin S, Munish VG, Sinha DN, Gupta PC, Swasticharan L. Patterns and related factors of bidi smoking in India. Tob Prev Cessat. 2020;6:28. https://doi.org/10.18332/tpc/119053.

15. Garrett BE, Martell BN, Caraballo RS, King BA. Socioeconomic Differences in Cigarette Smoking Among Sociodemographic Groups. Prev Chronic Dis. 2019;16:180553. http://doi.org/10.5888/pcd16.180553
16. Jindal SK, Aggarwal AN, Chaudhry K, Chhabra SK, D'Souza GA, Gupta D, et al. Asthma Epidemiology Study Group. Tobacco smoking in India: prevalence, quit-rates and respiratory morbidity. Indian J Chest Dis Allied Sci. 2006;48(1):37-42.

17. Kar SS, Sivanantham P, Rehman T, Chinnakali P, Thiagarajan S. Willingness to quit tobacco and its correlates among Indian tobacco users-Findings from the Global Adult Tobacco Survey India, 2016-17. J Postgrad Med. 2020;66(3):141-148. https://doi.org/10.4103/jpgm.JPGM_408_19.

18. Srivastava S, Malhotra, S., Harries, A.D. et al. Correlates of tobacco quit attempts and cessation in the adult population of India: secondary analysis of the Global Adult Tobacco Survey, 2009-10. BMC Public Health 13, 263 (2013). https://doi.org/10.1186/1471-2458$13-263$

19. Reddy MM, Kanungo S, Naik BN, Kar SS. Willingness to quit tobacco smoking and its correlates among Indian smokers - Findings from Global Adult Tobacco Survey India, 2009-2010. J Family Med Prim Care 2018;7:1353-6o. https://doi.org/10.4103/jfmpc.jfmpc_169_18

20. Chandra P, Govindraju P. Prevalence of oral mucosal lesions among tobacco users. Oral Health Prev Dent. 2012;10(2):149-53.

21. Aslesh OP, Paul S, Paul L, Jayasree A K. High Prevalence of Tobacco Use and Associated Oral Mucosal Lesion Among Interstate Male Migrant Workers in Urban Kerala, India, Int J Cancer Manag. 2015 ; 8(6):e3876. https://doi.org/10.17795/ijcp-3876. 
Cite this article as:

Nagar P, Abraham L, Bhati I. Tobacco Habits, Oral Mucosal Lesions and

Counselling Provided to Support Staff of Educational Institutions Situated in

Greater Noida, Uttar Pradesh, India: A Cross-Sectional Study. Int Healthc Res J.

2021;5(4)OR5-OR10. https://doi.org/10.26440/IHRJ/0504.07440

AUTHOR AFFILIATIONS: (*Corresponding Author)

1. GNM, Private Nursing Practitioners, Greater Noida, India

2. MDS (Orthodontics), Dharan, Nepal

Source of support: Nil, Conflict of interest: None declared 